\title{
Introduction
}

\section{The Teaching and Learning Technology Programme}

\author{
Sarah Turpin and Emma Greenwood \\ TLTP National Co-ordination Team, Northavan House, Coldharbour Lane, Bristol BS16 1QD, UK
}

\section{Introduction}

The UK higher education funding bodies have always been keen to promote good practice in teaching, learning and research, as well as in the overall management of higher education institutions. Since their establishment in 1992, the funding bodies have funded, either individually or jointly, over thirty special initiatives to develop learning opportunities, scholarship and management practice.

With rapid and constant changes within higher education, the funding bodies have sought to identify ways of funding activities focused on meeting specific needs within institutions, those of both students and staff. One of the main areas has been learning and teaching as institutions come under increasing pressure to respond to changing needs and a more diverse range of students. A number of factors are forcing institutions to rethink the way they deliver their learning and teaching including:

- declining resources but increasing student population;

- widening access and managing a more diverse student body;

- meeting industry's needs in providing students with transferable skills;

- competing in a global education market;

- changing student needs and demands for more flexible provision.

Commitment by higher education to deliver the highest quality learning and teaching is acknowledged through the funding bodies' Teaching Quality Assessment mechanism which is one driver for institutions to review their teaching practices and methods of delivery. The Quality Assessment procedures include seeking evidence that institutions are making appropriate and effective use of innovative methods such as information technology in their teaching. The use of such innovative methods is well supported in the UK by a well developed technological infrastructure in the form of JANET and SuperJANET.

\section{The Teaching and Learning Technology Programme (TLTP)}

The Teaching and Learning Technology Programme (TLTP) was launched in the belief that the higher education sector could benefit as a whole from collective activity in the area of developments in new technologies for learning and teaching. The Programme is, to the best of our knowledge, one of the largest technology based initiatives of its kind within higher education in the world. Launched in 1992 
by the Universities Funding Council, and continued by the four successor funding bodies, approximately $£ 70$ million has been invested in the programme, which involves over 140 universities and colleges.

The aim of the Programme was to "make teaching and learning more productive and efficient by harnessing modern technology". It quickly emerged that a three year materials development programme was not going to yield the sorts of results originally anticipated by the funding bodies and that an emphasis also needed to be placed on improving and maintaining quality within learning and teaching. The aim of achieving productivity and efficiency gains was accepted as being a much longer term one.

\section{TLTP phases 1 and 2}

The first two phases which ran from August 1992 to December 1996, focused on developing new technology based materials for learning and teaching and exploring, at an institutional level, different approaches to implementation. Each phase invited bids from institutions for funding up to three years. A huge amount of interest was shown by institutions, most notably in phase 2, when some 360 bids were received for total funding of $£ 3.75$ million annually for three years. It was only possible to fund 33 of these bids under this phase; 43 were funded in phase 1 .

Of the 76 projects from the first two phases, approximately three quarters of the projects worked in subject-based consortia developing materials for teaching first year undergraduates. They spanned a broad range of subject disciplines as well as a wide variety of approaches to development. The remaining institutional projects focused on the introduction and implementation of technology based materials together with the associated staff development.

The development projects have produced a wide range of materials for learning and teaching comprising interactive software and supporting documentation. The range of materials include some of the following:

- tutorial-replacement materials,

- case studies,

- databases and datasets,

- simulations,

- microworlds,

- revision materials,

- assessment.

As part of the bidding criteria, the funding bodies requested that institutions work together in consortia to encourage greater collaboration and pooling of resources and expertise. In some cases, up to as many as 50 different institutions participated in one project working with a large number of academic staff to produce high quality materials. This approach also assisted the dissemination process considerably through encouraging greater ownership at the outset as well as beginning to address the "not invented here" syndrome. Whilst there is still some way to go to completely overcome this syndrome, TLTP has certainly begun to challenge it.

\section{TLTP phase 3}

In July 1997, a third phase of the Programme was announced. Funding of up to $£ 3.5$ million annually for three years has been made available by two of the higher education funding bodies, the Higher 
Education Funding Council for England (HEFCE) and the Department for Education in Northern Ireland (DENI). Whereas the first two phases of TLTP focused largely upon the development of new technology based materials, the focus of this new phase is on implementation; embedding the use of technology more firmly into higher education learning and teaching and evaluating its effectiveness. As yet there is little known about the real cost and educational effectiveness of such technologies, so these areas will be explored in more detail as part of this phase.

HEFCE and DENI have commissioned the Tavistock Institute to work with TLTP over the three years of this phase on the formative evaluation; they will be preparing an evaluation framework and guidelines that will support the individual projects and the programme as a whole. The main purpose of this work will be to ensure that emerging lessons from the Programme are made available to the wider higher education community. The work will also be to assist project development and monitor the extent to which the Programme wide objectives are achieved, which are to:

- encourage the take-up and integration of TLTP materials and other technology based materials into mainstream learning and teaching;

- explore, adapt and disseminate experience from integrating such materials, to identify successful approaches that can be applied generically, rather than just to specific subjects;

- develop effective networks to deliver materials to end users;

- encourage continuing collaboration between higher education providers to develop and implement materials, using standard delivery environments.

The projects being funded cover a wide range of different approaches to implementation within a variety of subject disciplines, including: archaeology, economics, pharmacology, medicine and the health sciences, concrete technology, nursing, the built environment, art and design, electronic design, history and music. There are also a number of projects which are generic in nature, for example, exploring the use of technology in key skills development, computer aided assessment and small group teaching.

The expected outcomes and deliverables from this phase of the Programme are:

- new, enhanced or extended, technology based materials (some available via the Web);

- resource packs;

- generic Good Practice guides;

- centres of excellent, both physical and virtual;

- case studies;

- conference papers and reports;

- workshops and conferences.

\section{Ongoing support and maintenance}

Towards the end of the first two phases, the funding bodies recognised the importance of ongoing support and maintenance of the materials developed within TLTP. As a result a further $£ 4$ million was made available to projects to assist them to move from mainstream funding to a self-supporting position. Of the 76 original projects, 35 were awarded transitional funding following submission of business plans demonstrating how they would seek to obtain self-supporting status. Many of these projects have been successful in obtaining a high profile, with 15 projects now working with publishers to market and distribute their materials world-wide. There is also collaboration with other commercial partners such as BT, RSA and IBM. 
These projects are seeking to exploit their materials through sales to markets outside UK higher education. A number of the projects have developed, or are developing, in conjunction with publishers supporting materials to accompany their CD-ROMs, for example, student workbooks. Projects are expected to use income generated to maintain and upgrade their existing materials and continue to support UK higher education. Some of the projects have formed user clubs and these are being run on a subscription basis. Many of them have already achieved high levels of take-up in UK higher education.

\section{Overseas promotion}

Overseas institutions and organisations have also demonstrated considerable interest in TLTP. Some of this has been generated through a range of promotional activities by both the individual projects and the National Co-ordination Team. These include the production of a promotional CD-ROM containing samples of a range of TLTP material, and a 'TLTP Catalogue of Materials' specifically for use overseas. Visits to China, Australia and Malaysia by project staff and the National Co-ordinator have proved extremely successful and have laid the foundations for future collaboration. The British Council have also been responsible for promoting the programme at exhibitions and trade fairs. The growing success of the programme overseas is reflected in the increasing number of sales of materials to overseas institutions.

\section{Teaching and Learning Technology Support Network (TLTSN)}

An additional strand of the Programme, has been the establishment of the Teaching and Learning Technology Support Network in 1996. The purpose of this Network was to put in place a vehicle to assist the dissemination of experience and expertise from the TLTP institutional projects. The main aim of this support network is to provide advice and guidance to higher education institutions on the development and implementation of new technology based materials at the strategic level. They provide support, in the main, to senior and middle management within institutions looking to develop new strategies for the use of new technology based materials in learning and teaching. They often work with institutional management to support organisational and technological change and to assist with the formulation or review of learning technology policies.

The Support Network comprises nine of the original TLTP institutional projects from phases 1 and 2 . Each of the Centres within the TLTSN focus their activities regionally and regularly work together to provide the most appropriate support for each client institution. They provide free advice and guidance to senior and middle management within institutions and this takes a variety of forms such as meetings, workshops, seminars, presentations and one-to-one discussions. The Centres have also produced a series of case studies drawn from their own institutional experiences.

\section{Further developments}

Following the high level of interest in the first phase of TLTP, the four funding bodies have continued to actively promote the dissemination of good practice and encourage collaboration between institutions where it is believed that greater benefits can be achieved. Examples of such activities are:

- Computers in Teaching Initiative;

- Learning Technology Dissemination Initiative; 
- Use of Metropolitan Area Networks Initiative;

- Electronic Libraries Programme.

In addition to these initiatives which focus in some way on the role and use of information technology, the Council has also launched a Fund linked directly to the Teaching Quality Assessment - the Fund for the Development of Teaching and Learning. This Fund has been established to support the dissemination of good practice within learning and teaching.

\section{Key learning points}

During the four years of TLTP, the funding bodies, projects, institutions and higher education community at large, have built up a considerable amount of experience and it is important that the learning which has taken place is captured and transferred between and across institutions. Inevitably, there has been duplication of effort and reinventing of wheels within the programme but as long as the learning can be disseminated from the individual projects, these experiences can continue to benefit others in the longer term. Some of the key learning points for the programme have been in areas such as:

- project management;

- development strategies;

- evaluation;

- dissemination;

- copyright and intellectual property rights.

Whilst TLTP offers a set of tools together with knowledge and expertise, these have to be considered within the organisational context of institutions which continue to face the challenge of delivering more teaching for less resources. As academic staff have to find new and more efficient ways of delivering their teaching, and making the shift from teaching to learning, there is increasing pressure to exploit the new technologies and some of these are in the form of TLTP type materials.

Institutions are having to address a number of major challenges in this area such as:

- creating environments which foster and encourage innovation in teaching;

- developing learning and teaching strategies with technology as an integral part;

- keeping pace with technological advances;

- offering rewards/incentives for teaching;

- providing staff development and training for teachers.

It is clear from the positive response to initiatives such as TLTP, and the many examples of creative and interesting activities within institutions, that the higher education sector places great emphasis on the importance of the role of technology in learning and teaching. An evaluation study, carried out by Coopers \& Lybrand in 1996, found evidence of investment in technology by institutions, for example, the establishment of learning and teaching committees and a greater focus on staff development activities. However, the study stated that it was still difficult to find evidence of widespread cultural change as much of the activity takes place within isolated pockets driven by enthusiasts.

\section{Conclusion}

It is important to continue to reflect on the processes and experiences of TLTP and other similar initiatives as the technologies continue to advance ever more rapidly and the higher education sector is 
faced with greater challenges. If higher education is to meet the changing and more complex needs of society, there needs to be a recognition and understanding of how institutions must change in order to do this successfully. It is only through this that new and innovative methods of learning and teaching can ever be fully embraced, and as part of this, new technologies exploited to achieve the maximum benefits.

We should continue to ensure that the significant learning which takes place in initiatives such as TLTP is captured and shared as widely as possible amongst institutions. This experience should be built upon and not left to fade into the mists of time. 